\title{
The added value of centres of expertise for rare disease patients in Europe
}

\author{
Anna A Kole, Yann le Cam* \\ From 5th European Conference on Rare Diseases (ECRD 2010) \\ Krakow, Poland. 13-15 May 2010
}

In many European Union (EU) Member States (MS), rare disease (RD) patients are subject to marginalisation in classic healthcare systems designed for non-rare diseases. As a result they do not experience equal access to timely, high quality health services they deserve. The restructuring of healthcare systems to better reflect the values of equity and solidarity amongst RD patients, professionals, and policy makers across Europe can be accomplished through the establishment of Centres of Expertise (CoE).

Although no official definition of CoE exists, some MS have established physical expert structures for the management and care of RD patients at the national level. Specialising in a single RD or a group of RDs, CoE are ideally care centres that bring together a group of multidisciplinary, specialised competencies and ensure timely diagnosis and appropriate follow-up care by aiming to improve the continuity and coordination of care through the implementation of healthcare pathways.

In addition to providing an added value to the quality of local healthcare services, $\mathrm{CoE}$ are also key determinants for research on rare diseases, and support the optimisation of healthcare spending in the current economic climate. Stakeholders across Europe in the rare disease community have worked together to establish several key policy elements synthesized in the Eurordis Policy Factsheet on CoE.

In order to best establish, manage, and sustain longterm functioning of $\mathrm{CoE}$, monitoring systems must be established appropriate for each disease and national context. Building on the previous work of many stakeholders in this discussion, MS across Europe should work toward the establishment of $\mathrm{CoE}$ as possibly the most crucial elements in the context of national plans

* Correspondence: yann.lecam@eurordis.org

European Organisation for Rare Diseases, Paris, 75014, France and strategies. Although much success has been observed in the establishment of $\mathrm{CoE}$ in several MS, several challenges for future national strategies on $\mathrm{CoE}$ remain and are identified here.

Published: 19 October 2010

doi:10.1186/1750-1172-5-S1-04

Cite this article as: Kole and le Cam: The added value of centres of expertise for rare disease patients in Europe. Orphanet Journal of Rare Diseases 2010 5(Suppl 1):04.
Submit your next manuscript to BioMed Central and take full advantage of:

- Convenient online submission

- Thorough peer review

- No space constraints or color figure charges

- Immediate publication on acceptance

- Inclusion in PubMed, CAS, Scopus and Google Scholar

- Research which is freely available for redistribution

Submit your manuscript at www.biomedcentral.com/submit
C Biomed Central 